\title{
Developmental status of human immunodeficiency virus-exposed uninfected premature infants compared with premature infants who are human immunodeficiency virus unexposed and uninfected
}

\begin{tabular}{|c|c|}
\hline \multicolumn{2}{|c|}{$\begin{array}{l}\text { Authors: } \\
\text { Charne Cox }{ }^{1} \\
\text { Joanne Potterton } \\
\text { Samantha Rosie }\end{array}$} \\
\hline \multicolumn{2}{|c|}{$\begin{array}{l}\text { Affiliations: } \\
{ }^{1} \text { Department of } \\
\text { Physiotherapy, Faculty of } \\
\text { Health Sciences, University } \\
\text { of the Witwatersrand, } \\
\text { Johannesburg, South Africa }\end{array}$} \\
\hline \multicolumn{2}{|c|}{$\begin{array}{l}\text { Corresponding author: } \\
\text { Charne Cox, } \\
\text { charnecox@yahoo.com }\end{array}$} \\
\hline \multicolumn{2}{|c|}{$\begin{array}{l}\text { Dates: } \\
\text { Received: } 13 \text { Oct. } 2019 \\
\text { Accepted: } 20 \text { Mar. } 2020 \\
\text { Published: } 18 \text { June } 2020\end{array}$} \\
\hline \multicolumn{2}{|c|}{$\begin{array}{l}\text { How to cite this article: } \\
\text { Cox, C., Potterton, J. \& } \\
\text { Rosie, S., 2020, } \\
\text { 'Developmental status of } \\
\text { human immunodeficiency } \\
\text { virus-exposed uninfected } \\
\text { premature infants compared } \\
\text { with premature infants who } \\
\text { are human immunodeficiency } \\
\text { virus unexposed and } \\
\text { uninfected', South African } \\
\text { Journal of Physiotherapy } \\
76(1), \text { a1401. https://doi. } \\
\text { org/10.4102/sajp.v76i1.1401 }\end{array}$} \\
\hline \multicolumn{2}{|c|}{$\begin{array}{l}\text { Copyright: } \\
\text { (c) 2020. The Authors. } \\
\text { Licensee: AOSIS. This work } \\
\text { is licensed under the } \\
\text { Creative Commons } \\
\text { Attribution License. }\end{array}$} \\
\hline \multicolumn{2}{|l|}{ Read online: } \\
\hline 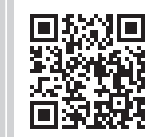 & $\begin{array}{l}\text { Scan this QR } \\
\text { code with your } \\
\text { smart phone or } \\
\text { mobile device } \\
\text { to read online. }\end{array}$ \\
\hline
\end{tabular}

Authors:

\section{Affiliations:}

Health Sciences, University of the Witwatersrand,

Corresponding author:

Charne Cox,

Dates:

Accepted: 20 Mar. 2020

How to cite this article: Cox, C., Potterton, J. \&

Rosie, S., 2020,

virus-exposed uninfected premature infants compared virus unexposed and uninfected', South African Journal of Physiotherapy 76(1), a1401. https://doi.

Copyright: Licensee: AOSIS. This work

is licensed under the

Creative Commons
Background: There is growing concern about the developmental outcome of infants exposed to HIV in utero. HIV-infected women are at greater risk of premature delivery which poses a further developmental risk factor.

Objectives: To determine whether there is a difference between the development of premature infants born at 28-37 weeks gestational age that are HIV exposed but uninfected (HEU) compared with HIV-unexposed uninfected infants (HUU).

Method: A cross-sectional study was conducted in a Johannesburg state hospital. Thirty HEU and $30 \mathrm{HUU}$ infants, aged between 16 days and six months, were assessed using the Bayley Scales of Infant and Toddler Development III.

Results: The two groups were well matched for gestational age and birth weight; however, more HUU infants presented with neonatal complications. HUU infants had lower developmental scores than HEU infants in the language $(p=0.003)$ and motor $(p=0.037)$ subscales. Expressive language was more affected in the HUU infants $(p=0.001)$, and fine $(p=0.001)$ and gross motor $(p=0.03)$ were affected as well. HUU infants with neonatal complications such as meningitis $(p=0.02)$ and neonatal jaundice $(\mathrm{NNJ})(p=0.01)$ are more likely to present with language and motor delay.

Conclusion: Meningitis and NNJ have more impact on infant development than in-utero HIV and ARV exposure.

Clinical implications: It is important for all premature infants to be screened regularly in order to diagnose developmental delays early so as to ensure early intervention and improved quality of life.

Keywords: HIV exposed; premature; development; infants; neonatal complications; neonatal jaundice.

\section{Introduction}

South Africa is responsible for $70 \%$ of all new human immunodeficiency virus (HIV) infections globally (UNAIDS 2013). Human immunodeficiency virus-positive women who are not on antiretrovirals (ARVs) may transmit the infection to their babies during the in utero and intrapartum periods as well as postpartum through breastfeeding (Hilburn, Potterton \& Stewart 2010). Human immunodeficiency virus mother-to-child transmission has been declining since 2008, when it was 8.5\%. By 2016 it was reported to be 1.5\% (Department of Health 2014, 2016). According to the World Health Organization (WHO), 73\% of all pregnant women living with HIV in 2014 obtained medication to prevent transmission to their babies and $32 \%$ of children received HIV treatment.

An estimated 15 million babies are born prematurely every year (WHO, 2018). The incidence of preterm birth varies from one community to another and depends on a number of factors (Castell et al. 2013). These factors include low socio-economic status, poor maternal nutrition, maternal age, limited antenatal care, poor healthcare, heavy manual labour, maternal substance abuse, maternal hypertension, maternal diabetes, maternal stress and anxiety, twin pregnancies, trauma and infections (Castell et al. 2013; De Jongh et al. 2014; Irshad et al. 2012; Piscoya et al. 2012; Xu et al. 2015). Studies have shown that premature delivery is more frequent in HIV-positive women 
(Fiore et al. 2007; Powis et al. 2011; Traisathit et al. 2009). This could be because of severe immunosuppression from delayed antiretroviral therapy (ART) initiation, an increase risk for opportunistic infections as well as poor weight gain (Ezechi et al. 2013).

Premature infants are at an increased risk for growth failure, cerebral palsy, developmental delay and mental retardation (Saigal \& Doyle 2008).

Many studies have found a correlation between HIV exposure and prematurity, low birth weights (LBW), intrauterine growth retardation, foetal death, neonatal mortality and respiratory complications (Darak et al. 2013; Nlend et al. 2016; Salihu et al. 2012). The developmental outcomes of HIVexposed infants are still poorly researched and understood (Salihu et al. 2012).

Barret et al. (2003) found that infants exposed to ARVs during the perinatal period are at risk of poor neurological outcomes, such as cognitive delay, behavioural problems, motor abnormalities and convulsions, because of the continual mitochondrial dysfunction. The aim of our study was therefore to determine if there is a difference between the development of premature infants born at 28-37 weeks of gestational age that are HIV-exposed uninfected (HEU) compared to HIV-unexposed uninfected (HUU) infants at 16 days to 6 months of corrected age.

Very little research has been carried out on this topic in Southern Africa and not for infants aged 16 days to 6 months. If we can detect any developmental problem at a young age, we can begin early intervention at a younger age and potentially reduce the impact of HIV exposure on the child.

\section{Methodology}

Our study was cross sectional. Participants were recruited from the neonatal follow-up clinic at Tambo Memorial Hospital (TMH) in South Africa. This clinic provides follow-up services for at-risk infants and includes those discharged from neonatal intensive care and those born prematurely.

A sample of convenience was used and the mothers of consecutive infants who met the inclusion criteria were invited to participate. Infants were included if they had a gestational age of 28-37 weeks and presented at the clinic between 16 days and 6 months of corrected age. HIV-exposed uninfected and HUU infants were eligible for inclusion. Infants were not eligible for inclusion if maternal HIV status was not known or if the infant presented with clinically obvious congenital conditions such as spina bifida.

A total of 60 infants (30 HEU and $30 \mathrm{HUU}$ infants) met the inclusion criteria and their caregivers agreed to participate in the study. The sample size was calculated using the Bayley scales of Infant Development (BSID) III, 27 infants per group allowed for a power of $90 \%$ and a confidence interval of \pm 4.63 .
Infants were assessed using the BSID III in a quiet room. The BSID is considered to be the gold standard for infant developmental assessment globally. It has sound, wellestablished psychometric properties. The intra-rater reliability coefficients are excellent for the cognitive scale (Intraclass Correlation Coefficient (ICC) $=0.92-0.99$ ) and good to excellent for the language (ICC $=0.88-0.98$ ) and motor scale (ICC $=0.85-0.98)$. The inter-rater reliability coefficients are good to excellent for the cognitive (ICC = $0.87-0.97$ ) and language scale (ICC $=0.76-0.95)$ and good for the motor scale (ICC $=0.77-0.89$ ) ( $Y$, et al. 2013). Caregivers completed a demographic information form which took approximately $10 \mathrm{~min}$ and clinical history was obtained from the infant's hospital file.

Descriptive statistics were conducted to condense the raw data with regard to information on the development of HUU and HEU infants. Tests used were means, standard deviation (SD) and confidence intervals (CIs). The level of significance was set at 0.05 .

Inferential statistics were used to determine the differences between HUU and HEU infants. Test used was independent $t$-test as the groups are unrelated.

\section{Ethical consideration}

Ethical clearance was obtained from the Human Research Ethics Committee (Medical) University of the Witwatersrand (clearance number: M160438). Caregivers of the infants provided informed consent to participate before any assessments were done.

\section{Results}

The infants in the two groups were well matched for demographic information. The mean gestational age (SD) was 33.13 weeks (2.43) for the HEU group and 33.20 (2.57) weeks for the HUU group ( $p=0.98)$. There were $43(71.67 \%)$ infants in the late preterm category (32-27 weeks), 17 (28.33\%) infants in the very preterm category (28-32 weeks) and no infants in the extremely preterm category ( $<28$ weeks). The mean corrected age in the HIV-exposed group at the time of assessment was 2.26 months and in the unexposed group it was 2.9 months $(p=0.09)$. The majority of infants were born with an LBW (67\%) and there was no significant difference between the two groups for birth weight categories $(p=0.50)$ (see Table 1).

The clinical history of the two groups was similar for most factors assessed (see Table 2). A significant difference $(p=0.02)$ was seen in the number of infants who had a history of meningitis, with more HUU infants affected. Sixty-seven per cent of infants in the HUU group compared with $37 \%$ in the HEU group had a history of neonatal jaundice (NNJ) $(p=0.01)$.

The composite scores of the BSID III were compared. There was no significant difference in the means of the cognitive 
TABLE 1: Demographic information for human immunodeficiency virus exposed uninfected and human immunodeficiency virus-unexposed uninfected groups.

\begin{tabular}{|c|c|c|c|c|c|}
\hline \multirow[t]{2}{*}{ Variable } & \multicolumn{2}{|c|}{ HEU $(n=30)$} & \multicolumn{2}{|c|}{ HUU $(n=30)$} & \multirow[t]{2}{*}{$p$} \\
\hline & Number & $\%$ & Number & $\%$ & \\
\hline \multicolumn{6}{|c|}{ Birth weight } \\
\hline ELBW & 2 & 6.7 & 3 & 3 & 0.50 \\
\hline VLBW & 5 & 16.7 & 10 & 17 & \\
\hline LBW & 20 & 66.7 & 40 & 67 & \\
\hline AVG & 3 & 10 & 7 & 13 & \\
\hline \multicolumn{6}{|c|}{ Gestational age } \\
\hline Mean & 33.13 & 2.43 & 33.20 & 2.57 & 0.98 \\
\hline Median & 33.5 & - & 33.00 & - & \\
\hline
\end{tabular}

ELBW, extremely low birth weight; HEU, HIV-exposed uninfected; HUU, HIV-unexposed uninfected; VLBW, very low birth weight; LBW, low birth weight; AVG, average.

TABLE 2: Complications for human immunodeficiency virus-exposed uninfected and human immunodeficiency virus-unexposed uninfected groups.

\begin{tabular}{|c|c|c|c|c|c|}
\hline \multirow[t]{2}{*}{ Variable } & \multicolumn{2}{|c|}{ HEU $(n=30)$} & \multicolumn{2}{|c|}{ HUU $(n=30)$} & \multirow[t]{2}{*}{$p$} \\
\hline & Number & $\%$ & Number & $\%$ & \\
\hline \multicolumn{6}{|c|}{ Hydrocephalus } \\
\hline No & 29 & 97 & 29 & 97 & 0.50 \\
\hline Yes & 1 & 3 & 1 & 3 & \\
\hline \multicolumn{6}{|c|}{ RDS/HMD } \\
\hline No & 7 & 23 & 8 & 27 & 0.38 \\
\hline Yes & 23 & 77 & 22 & 73 & \\
\hline \multicolumn{6}{|c|}{ Mechanical Ventilation } \\
\hline No & 18 & 60 & 23 & 77 & 0.08 \\
\hline Yes & 12 & 40 & 7 & 23 & \\
\hline \multicolumn{6}{|c|}{ Supplementary Oxygen } \\
\hline No & 6 & 20 & 6 & 20 & 0.50 \\
\hline Yes & 24 & 80 & 24 & 80 & \\
\hline \multicolumn{6}{|l|}{ CLD } \\
\hline No & 28 & 93 & 30 & 100 & 0.08 \\
\hline Yes & 2 & 7 & 0 & 0 & \\
\hline \multicolumn{6}{|c|}{ Pneumonia } \\
\hline No & 26 & 87 & 29 & 97 & 0.08 \\
\hline Yes & 4 & 13 & 1 & 3 & \\
\hline \multicolumn{6}{|l|}{ NNJ } \\
\hline No & 19 & 63 & 10 & 33 & 0.01 \\
\hline Yes & 11 & 37 & 20 & 67 & \\
\hline \multicolumn{6}{|l|}{ NNS } \\
\hline No & 21 & 70 & 21 & 70 & 0.50 \\
\hline Yes & 9 & 30 & 9 & 30 & \\
\hline \multicolumn{6}{|c|}{ Meningitis } \\
\hline No & 30 & 100 & 26 & 87 & 0.02 \\
\hline Yes & 0 & 0 & 4 & 13 & \\
\hline \multicolumn{6}{|c|}{ ICU admission } \\
\hline No & 17 & 57 & 22 & 73 & 0.09 \\
\hline Yes & 13 & 43 & 8 & 27 & \\
\hline \multicolumn{6}{|l|}{ KMC } \\
\hline No & 23 & 77 & 19 & 63 & 0.13 \\
\hline Yes & 7 & 23 & 11 & 37 & \\
\hline
\end{tabular}

RDS/HMD, respiratory distress syndrome/Hyaline membrane disease; CLD, chronic lung disease NNJ, neonatal jaundice; NNS, neonatal sepsis; ICU, intensive care unit; KMC, Kangaroo mothe care; HEU, HIV-exposed uninfected; HUU, HIV-unexposed uninfected.

Bold text describe the unexpected results from the standardised outcome measure used for these factors.

composite scores between groups $(p=0.97)$. Language $(p=0.00)$ and motor $(p=0.04)$ composite scores showed a significant difference between the groups, with the HUU having lower developmental scores. All mean composite scores fell within 1 SD of the norm (Table 3).

When comparing expressive and receptive language scaled scores, the expressive language was more affected $(p=0.00)$ in the HUU infants. Scaled scores of both fine motor $(p=0.00)$
TABLE 3: Developmental scores for human immunodeficiency virus-exposed uninfected and human immunodeficiency virus-unexposed uninfected premature infants.

\begin{tabular}{lcccccc}
\hline Variable composite scores & \multicolumn{2}{c}{ HEU $(\boldsymbol{n}=\mathbf{3 0})$} & & \multicolumn{2}{c}{ HUU $(\boldsymbol{n}=\mathbf{3 0})$} & \multirow{2}{*}{$\boldsymbol{p}$} \\
\cline { 2 - 3 } & Mean & SD & & Mean & SD & \\
\hline Cognitive & 98.20 & 13.68 & 98.30 & 20.14 & 0.97 \\
Language & 99.30 & 9.70 & 91.40 & 10.31 & $<0.001^{*}$ \\
Motor & 104.70 & 12.95 & 96.70 & 15.77 & $0.04^{*}$ \\
\hline
\end{tabular}

HEU, HIV-exposed uninfected; HUU, HIV-unexposed uninfected; SD, standard deviation.

*, Statistical significant difference.

TABLE 4: Scaled scores for human immunodeficiency virus-exposed uninfected and human immunodeficiency virus-unexposed uninfected premature infants.

\begin{tabular}{lccccccc}
\hline Scaled scores & \multicolumn{2}{c}{ HEU $(\boldsymbol{n}=\mathbf{3 0})$} & & \multicolumn{2}{c}{ HUU $(\boldsymbol{n}=\mathbf{3 0})$} & \multirow{2}{*}{$\boldsymbol{p}$} \\
\cline { 2 - 3 } & Mean & SD & & Mean & SD & \\
\hline Language & 19.9 & 3.40 & & 17.0 & 3.56 & $<0.001^{*}$ \\
Expressive & 10.8 & 1.95 & & 8.4 & 2.19 & $<0.001^{*}$ \\
Receptive & 9.0 & 1.71 & & 8.6 & 2.16 & 0.40 \\
Motor & 22.3 & 2.30 & & 18.8 & 5.21 & $<0.001^{*}$ \\
Fine & 11.2 & 1.61 & & 9.0 & 2.72 & $<0.001^{*}$ \\
Gross & 11.1 & 1.31 & & 9.8 & 2.83 & $0.03^{*}$ \\
\hline
\end{tabular}

HEU, HIV-exposed uninfected; HUU, HIV-unexposed uninfected; SD, standard deviation.

*, Statistical significant difference.

TABLE 5: Proportion of infants delayed or at risk for delay - Neonatal jaundice.

\begin{tabular}{|c|c|c|c|c|c|c|c|}
\hline \multirow[t]{2}{*}{ Subscale } & \multicolumn{2}{|c|}{$\begin{array}{c}\text { Delayed } \\
\text { (score }<70)\end{array}$} & \multicolumn{2}{|c|}{$\begin{array}{c}\text { At risk } \\
\text { (score 70-85) }\end{array}$} & \multicolumn{2}{|c|}{$\begin{array}{c}\text { TD } \\
(\text { score }>85)\end{array}$} & \multirow{2}{*}{$\begin{array}{c}p \text { (test difference in } \\
\text { proportions in delayed } \\
\text { between HEU and HUU) }\end{array}$} \\
\hline & $n$ & $\%$ & $n$ & $\%$ & $n$ & $\%$ & \\
\hline Cognitive & & & & & & & 0.09 \\
\hline HEU & 0 & 0.0 & 1 & 9.1 & 10 & 90.9 & \\
\hline HUU & 3 & 15.0 & 2 & 10.0 & 15 & 75.0 & \\
\hline Language & & & & & & & 0.23 \\
\hline HEU & 0 & 0.0 & 0 & 0.0 & 11 & 100.0 & \\
\hline HUU & 1 & 5.0 & 5 & 25.0 & 14 & 70.0 & \\
\hline Motor & & & & & & & $\mathrm{n} / \mathrm{a}$ \\
\hline HEU & 0 & 0.0 & 2 & 18.2 & 9 & 81.8 & \\
\hline HUU & 0 & 0.0 & 5 & 25.0 & 15 & 75.0 & \\
\hline
\end{tabular}

HEU, HIV-exposed uninfected; HUU, HIV-unexposed uninfected; n/a, not applicable; TD, Typical development.

and gross motor $(p=0.03)$ were significantly lower in the HUU infants (Table 4).

Although there were no significant differences between the two groups, the HUU group was more delayed in the cognitive subscale $(10 \%)$ and were at risk for delay in all subscales (6.7\% cognitive, $20 \%$ language, $20 \%$ motor) when compared with the HEU group.

Because of the discrepancy in history of NNJ and meningitis between the two groups, these two factors warranted further investigation. The number of children in each group with meningitis was too low to be able to undertake further statistical analysis; however, the children with NNJ could be compared. Infants with a history of NNJ had significantly lower composite scores in the language $(p=0.00)$ and motor $(p=0.05)$ aspects of development.

Fifteen per cent of the HUU NNJ infants showed cognitive delay, with $10 \%$ being at risk. Five per cent of the HUU NNJ infants showed language delay with $25 \%$ being at risk. None of the HUU infants with a history of NNJ showed delay in motor development, but $25 \%$ were at risk (Table 5). 


\section{Discussion}

Prematurity is a known risk factor for developmental delay (Guimaraes et al. 2011; Nepomnyaschy et al. 2012) and it affected both groups equally. Research has shown that pregnancy outcomes such as premature births (PTB) and LBW are associated with Protease inhibitor-based ART as well as the timing of the initiation of the ART (Darak et al. 2013; Mesfin, Kibret \& Taye 2016; Powis et al. 2011). A study conducted by Mesfin et al. (2016) showed that there is a $32 \%$ increased risk of PTB when a mother receives these Protease Inhibitor (PI)-based ART regimes, especially if it is given within the first trimester ( $<13$ weeks) and the third trimester. This is important as all the mothers in our study were receiving ART (Darak et al. 2013; Powis et al. 2011). Another study conducted by Darak et al. (2013) showed that $45 \%$ of women in their study had adverse pregnancy outcomes whereby there were 17\% PTB and $27 \%$ LBW.

Most infants were born with an LBW (1500 g - $2499 \mathrm{~g})$. Birth weight has been shown to have a negative impact on development (Ballot et al. 2012; Chaudhury et al. 2017; Oudgenoeg-Paz et al. 2017). It was found that children born with an LBW are at risk for poor quality of movement and postural control. It is this affected early motor development that may affect cognitive development at a later stage (Oudgenoeg-Paz et al. 2017). Low birth weight is a risk factor that affected both groups in our study with regard to motor and cognitive development.

Meningitis and neonatal jaundice are independent welldocumented causes of neurological impairment in neonates (Heath \& Okike 2010; Ku, Boggess \& Cohen-Wolkowiez 2015; Rosie, Potterton \& Pilusa 2016). In this particular group of infants, the HUU group had a higher prevalence of NNJ. A study conducted at Baragwanath Hospital in Soweto, South Africa, which investigated the neurodevelopmental outcome of 40 Neonatal Intensive Care Unit (NICU) survivors (mean gestational age 34 weeks), found that NNJ was a risk factor for abnormal language and motor development (Rosie, Potterton \& Pilusa 2016). This is similar to the findings in our study.

Recent studies have shown that HEU infants are at risk of opportunistic infections, such as pneumonia, tuberculosis and diarrhoea, all of which can have a major impact on the health and development of an infant (Evans, Jones \& Prendergast 2016; Rajan et al. 2017). This is in contrast to our study as complications such as pneumonia showed no significant differences between the two groups.

The developmental scores showed that the majority of the HEU infants did well in all aspects of development when compared with the HUU group. The mean developmental scores for the HEU infants were all within 1 SD of the norm and therefore showed typical development in this group of infants.
Much debate on the impact of intra-uterine exposure to HIV as well as ARVs still exists. Most of the studies that have been conducted have included infants born at term with little consideration of premature infants. A study conducted in India by Rajan et al. (2017) reported on the developmental outcome of 41 HEU infants aged 6-18 months, of whom 40 had typical development. This study concluded that the ARV drug exposure in utero had no effect on the development of these infants.

A South African study conducted in Cape Town in 2017 assessed the development of HEU infants at 12 months of age using the BSID III. The authors found there is a minor difference in neurodevelopmental outcome when compared with HUU infants (Springer et al. 2018). In contrast to our study, Springer et al. (2018) found that a higher proportion of HEU infants had a poorer developmental outcome with regard to language development. This study did not take prematurity into consideration and looked at other risk factors, such as socioeconomic characteristics, socio-demographic characteristics and anthropometric characteristics.

When looking at a study with older HEU children (24 months) in Botswana, there is still no negative neurodevelopmental outcome when assessed with the BSID III. They assessed 313 HEU infants and concluded that there was no negative neurodevelopmental impact on children when they are exposed to the HIV virus in utero or the ARV drugs (Chaudhury et al. 2017).

In our study, the HUU infants had lower developmental scores in expressive language as well as fine and gross motor subscales of the BSID III. This group had more neonatal complications such as meningitis and NNJ, and this seems to have had more of an effect on the infant's central nervous system (CNS) than HIV exposure.

Human immunodeficiency virus-exposed uninfected infants are likely to be born prematurely because of the ARVs during pregnancy in order for Prevention of Mother to Child Transmission (PMTCT) (Nlend et al. 2016); however, HUU infants are born prematurely when other complications or lifestyles arise (Saltani et al. 2017; Waetcher 2014).

Meningitis is a bacterial infection of the CNS and has the highest incidence in the neonatal period. The risk factors include prematurity, LBW, chorioamnionitis, prolonged rupture of membrane, premature rupture of membrane, low socio-economic status, need for resuscitation, prolonged hospitalisation and male infants (Heath \& Okike 2010; Ku, Boggess \& Cohen-Wolkowiez 2015). The more premature the infant, the worse the prognosis is and the more likely the infant will present with long-term neurodevelopmental complications (Heath \& Okike 2010; Ku, Boggess \& CohenWolkowiez 2015; Lin et al. 2012).

High levels of circulating bilirubin in neonates can have severe and serious consequences as the bilirubin can cross the blood-brain barrier and attach to the developing brain 
tissue. The most vulnerable areas of the infant's brain are those that control hearing and motor function (Casey 2013; Pearsall \& Morrow 2016).

Studies have shown that NNJ has an effect on the development of infants. Rosie et al. (2016) found that $37.5 \%$ of their 40 neonatal ICU survivors (mean gestational age 34 weeks) were treated for NNJ. These infants were found to be at risk for language and motor developmental delays. This was confirmed in our study as $25 \%$ of HUU infants with NNJ were at risk for language and motor delays, with only $10 \%$ being at risk for cognitive delay.

It would have been beneficial to follow up the infants at a later stage to determine whether their development would improve at a later age as the infants were very young. The small sample size and many possible confounding factors may have influenced the results of our study.

Our results suggest that HIV and ARV exposure in utero seem to have little effect on the development of an infant. Birth complications such as meningitis and NNJ have a much bigger negative impact on neonatal development. All premature infants, whether HEU or HUU, should have developmental follow-up post-discharge to ensure early intervention if the need arises.

Antiretrovirals in pregnancy are critical in preventing mother-to-child transmission of HIV and ensuring a healthier infant with less neurodevelopmental complications. Larger long-term follow-up studies are needed to monitor the developmental trajectories of infants exposed to HIV and ARVs in utero.

\section{Acknowledgements}

The authors would like to thank Gauteng Department of Health. Data collection took place at Tambo Memorial Hospital. They also thank Chris Christoforou for data analysis.

\section{Competing interests}

The authors have declared that no competing interest exists.

\section{Authors' contributions}

C.C. and J.P. were responsible for the conceptualisation of the study; C.C. and S.R. were involved in data collection and all three authors were involved in the write up of the study and approved the final version.

\section{Funding information}

This research received no specific grant from any funding agency in the public, commercial or not-for-profit sectors.

\section{Data availability statement}

Data sharing is not applicable to this article as no new data were created or analysed in this study.

\section{Disclaimer}

The views and opinions expressed in this article are those of the authors and do not necessarily reflect the official policy or position of any affiliated agency of the authors.

\section{References}

Barret, B., Tardieu, M., Rustin, P., Lacroix, C., Chabrol, B., Desquerre, I. et al., 2003 , 'Persistent mitochondrial dysfunction in HIV-1-exposed but uninfected infants: Clinical screening in a large prospective cohort', AIDS, 1769-1785.

Ballot, D.E., Potterton, J., Chirwa, T., Hilburn, N. \& Cooper, P.A., 2012, 'Developmental outcome of very low birth weight infants in a developing country', Biomedcentral Pediatrics, $1-10$

Casey, G. 2013, 'Jaundice: An excess of bilirubin', Kai Tiaki Nursing New Zealand, 20-24.

Castell, E., Rizo-Baeza, M., Aguilar Cordero, M., Rizo-Baeza, J. \& Gil Guillen, V. 2013, 'Maternal age as risk factor of prematurity in Spain; Mediterranean area', NutricionHospitalaria, 1536-1540.

Chaudhury, S., Williams, P.L., Mayondi, G.K., Leidner, J., Holding, P., Tepper, V. et al., 2017, 'Neurodevelopment of HIV-exposed uninfected children at 24 months', Pediatrics 140(4), 1-10. https://doi.org/10.1542/peds.2017-0988

Darak, S., Darak, T., Kulkarni, S., Kulkarni, V., Parchure, R., Hutter, I. et al., 2013, 'Effect of highly active antiretroviral treatment (HAART) during pregnancy on pregnancy outcomes: Experiences from a PMTCT Program in Western India', AIDS Patient Care and STDs 27(3), 163-172. https://doi.org/10.1089/apc.2012.0401

Department of Health 2013/2014, National Annual Report, viewed March 2016, from http://www.gov.za/sites/www.gov.za/files/Department_of_Health_Annual_ Report_2014.pdf.

Department of Health 2016/2017, National Annual Report, viewed March 2018, from http://www.gov.za/sites/www.gov.za/files/Department_of_Health_Annual Report_2016-17.pdf

De Jongh, B., Paul, D., Hoffman, M. \& Locke, R. 2014, 'Effects of pre-pregnancy obesity, race/ethnicity and prematurity', Maternal and Child Health Journal 511-517.

Ezechi, O., Gab-Okafor, C., Oladele, D., Kalejaiye, O., Oke, B., Ohwodo, H. et al., 2013, 'Pregnancy, obstetric and neonatal outcomes in HIV positive Nigerian women', African Journal of Reproductive Health 17(3), 160-168.

Evans, C., Jones, C.E. \& Prendergast, A.J. 2016, 'HIV-exposed, uninfected infants: New global challenges in the era of paediatric HIV elimination', The Lancet, e92-e107.

Fiore, S., Ferrazzi, E., Newell, M.-L., Trabattoni, D. \& Clerici, M., 2007, 'Protease inhibitor-associated increased risk of preterm delivery is an immuno-logical complication of therapy', The Journal of Infectious Diseases 195(6), 914-916. complication of therapy', The
https://doi.org/10.1086/511983

Heath, P.T. \& Okike, I.O. 2010, 'Neonatal bacterial meningitis: An update', Paediatrics and Child Health, 526-2530.

Guimaraes, C.L., Reinaux, C.M., Botelho, A.C., Lima, G.M. \& Cabral Filho, J.E. 2011 'Motor development evaluated by Test of Infant Motor Performance: Comparison between preterm and full-term infants', Brazilian Journal of Physical Therapy, 357-362.

Hilburn, N., Potterton, J. \& Stewart, A., 2010, 'Paediatric HIV encephalopathy in subSaharan Africa', Physical Therapy Reviews 15(5), 410-417. https://doi.org/10.1179/ 1743288X10Y.0000000013

Irshad, M., Ahmad, A., Ahmed, K., Hayat, M., Kareem, R., Hussain, M., et al. 2012, 'Risk factors for preterm births in a tertiary care hospital, Lady Reading Hospital, Peshawar', Journal of Postgraduate Medical Institute 158-164.

Lin, M.-C., Chi, H., Chiu, N.-C., Huang, F.-Y. \& Ho, C.-S. 2012, 'Factors for poor prognosis of neonatal bacterial meningitis in a medical center in Northern Taiwan', Journa of Microbiology, Immunology and Infection, 442-447.

Ku, L.C., Boggess, K.A. \& Cohen-Wolkowiez, M. 2015, 'Bacterial meningitis in infants', Clinical Perinatology, 29-45.

Mesfin, Y., Kibret, K. \& Taye, A., 2016, 'Is protease inhibitors based antiretroviral therapy during pregnancy associated with an increased risk of preterm birth? Systematic review and a meta-analysis', Reproductive Health 13, 1-9. https://doi. org/10.1186/s12978-016-0149-5

Nepomnyaschy, L., Hegyi, T., Ostfeld, B.M. \& Reichman, N.E. 2012, 'Developmental outcomes of late-preterm infants at 2 and 4 years', Maternal and Child Health Journal 1612-1624.

Nlend, A.E., Motaze, A.N., Tetang, S.M., Zeudja, C., Ngantcha, M. \& Tejiokem, M., 2016, 'Preterm birth and low birth weight after in utero exposure to anitretrovirals initiated during pregnancy in Yaounde, Cameroon', PLoS One 11(3), 1-10.

Powis, K., Kitch, D., Ogwu, A., Hughes, M., Lockman, S., Leidner, J. et al., 2011, Increased risk of preterm delivery among HIV-infected women randomized to protease versus nucleoside reverse transcriptase inhibitor - Based HAART during pregnancy', The Journal of Infectious Diseases 204(4), 506-514. https://doi.org/ 10.1093/infdis/jir307

Oudgenoeg-Paz, O., Mulder, H., Jongmans, M.J., van der Ham, I.J. \& van der Stigchel, S., 2017, 'The link between motor and cognitive development in children born preterm and/or with low birth weight: A review of current evidence', Neuroscience and Biobehavioral Reviews 80, 382-393.

Rosie, S., Potterton, J. \& Pilusa, S., 2016, Wits Institutional Repository environment on DSpace, viewed March 2018, from http://hdl.handle.net/10539/21314. 
Pearsall, R. \& Morrow, G., 2016, 'Jaundice in newborns', World of Irish Nursing, 51-52. Piscoya, M., Ximenes, R., Silva, G., Jamelli, S. \& Coutinho, S., 2012, 'Materna periodontitis as a risk factor for prematurity', Pediatrics International, 68-75.

Rajan, R., Seth, A., Mukherjee, S.B. \& Chandra, J., 2017, 'Development assessment of HIV exposed children aged 6-18 months: A cohort study from North India', AIDS Care, $1-7$.

Saigal, S. \& Doyle, L.W., 2008, 'An overview of mortality and sequelae of preterm birth from infancy to adulthood', The Lancet 371(9608), 261-269. https://doi. org/10.1016/S0140-6736(08)60136-1

Salihu, H., August, E., Aliyu, M., Stanley, K., Weldeselasse, H. \& Mbah, A., 2012 'Maternal HIV/AIDS status and neurological outcomes in neonates: A populationbased study', Maternal \& Child Health Journal 16, 641-648. https://doi.org/ 10.1007/s10995-011-0799-4

Saltani, H., Lipoeto, N.I., Fair, F.J., Kilner, K. \& Yusrawati, Y., 2017, 'Pre-pregnancy body mass index and gestational weight gain and their effects on pregnancy and birth outcomes: A cohort study in West Sumatra, Indonesia', BMC Women's Health 102-114
Springer, P.E., Slogrove, A.L., Laughton, B., Bettinger, J.A., Saunders, H.H., Molteno, C.D. et al., 2018, 'Neurodevelopmental outcome of HIV-exposed but uninfected infants in the Mother and Infants Health Study Cape Town, South Africa', Tropical Medicine \& International Health 23(1), 69-78. https://doi.org/10.1111/tmi.13006

Traisathit, P., Mary, J., Le Coeur, S., Thantanarat, S., Jungpichanvanich, S., Pornkitprasarn W. et al., 2009, 'Risk factors of preterm delivery in HIV-infected pregnant women receiving zidovudine for the prevention of perinatal HIV', Journal of Obstetrics \& Gynecology 35(2), 225-233. https://doi.org/10.1111/j.1447-0756.2008.00925.x

UNAIDS AIDS. Epidemic Update 2013, viewed January 2016, from http://www. unaids.org.

Waetcher, M., 2014, 'Malnutrition, unhealthy lifestyles and scheduled deliveries: The causes of prematurity', Midwifery Today, 38-39.

World Health Organization (WHO), 2018, Preterm birth, World Health Organization, viewed June 2018, from www.who.int/news-room/fact-sheets/detail/preterm-birth.

Xu, H., Dai, Q., Xu, Y., Gong, Z., Dai, G. \& Ding, M. et al. 2015, 'Time trends and risk factor associated with premature birth and infants deaths due to prematurity in Hube Province, China from 2001 to 2012', BioMedCentral Pregnancy and Childbirth, 329-339. 